\title{
9 Water Harvesting for Improved Rainfed Agriculture in the Dry Environments
}

\author{
T. Oweis* and A. Hachum \\ Integrated Water and Land Management Program, International Center for \\ Agricultural Research in the Dry Areas (ICARDA), Aleppo, Syria; \\ email:*t.oweis@cgiar.org
}

\section{Background and Definitions}

In the arid and semi-arid regions, precipitation is generally lower than potential evaporation, non-uniform in distribution, resulting in frequent drought periods during the crop growing season, and usually comes in intense bursts, resulting in surface run-off and uncontrolled rill and gully erosion.

In the cool winter areas, as in the Mediterranean type of climate, precipitation is less than $300 \mathrm{~mm}$, part of which is lost to evaporation and run-off. The amount stored in the root zone is well below crop water requirements. In dry (semi-arid) tropical areas, such as the Sahel zone in Africa, although mean precipitation is relatively higher $(500 \mathrm{~mm})$, a larger portion of precipitation is lost to evaporation.

\section{Where does rainwater in the dry environments go?}

A large part of the rainfall returns to the atmosphere directly by evaporation from the soil surface and also a part of that infiltrated into the soil to a small depth evaporates into the atmosphere with no benefits. The part that flows as run-off, if not intercepted, goes to slumps, losing its good quality and evaporating; it may even flow into the sea. It was estimated that only about $10 \%$ of the annual rainfall on the dry rangelands of West Asia and North Africa (WANA) is beneficially used for supporting vegetation cover, replenishing the groundwater and other purposes (Oweis and Taimeh, 2001).

Other factors, such as degraded soils, steep topography, poor vegetative cover and unfavourable climate, besides the poor rain characteristics, aggravate the problem, causing irreversible desertification and detrimental loss of both water and land productivity. Water harvesting $(\mathrm{WH})$ is one option that increases the amount of water per unit cropping area, reduces drought and enables use of run-off beneficially (Oweis et al., 1999).

\section{Concept and definition}

The principle of agricultural rainwater harvesting is based on the concept of depriving part of the land of its share of precipitation, which is usually small and non-productive, and giving it to another part to increase the amount of water available to the latter part, which originally was not sufficient, and to bring this amount closer to the crop water requirements so that an economical agricultural production can be achieved. Such concentration of precipitation in a smaller area is called water harvesting $(\mathrm{WH})$ and may be defined in various ways such as: 
- The process of collecting natural precipitation from prepared watersheds for beneficial use.

- Collecting and concentrating various forms of run-off from precipitation and for various purposes.

- The process of concentrating precipitation through run-off and storing it for beneficial use.

Critchley and Siegert (1991) simply define $\mathrm{WH}$ as 'collection of run-off for its productive use'. For Reij et al. (1988), it is a hydroagronomic term covering a whole range of methods of collecting and concentrating various forms of run-off. The concept of $\mathrm{WH}$, as described above, is different from the traditional soil-water conservation practices in which no part of the land is purposely deprived of its share of water. Soil-water conservation practices aim at preventing surface run-off and keeping rainwater in place, whereas $\mathrm{WH}$ makes use of, and even induces, surface run-off.

In the $\mathrm{WH}$ process the run-off-producing area is adjacent to the cropped area, and part of the land and most of the precipitation water will become productive. More importantly, agricultural production becomes possible, and the WH systems might be for a single purpose or for multi-purpose and built to serve domestic, agricultural, animal or environmental uses.

\section{Water harvesting in the past and the present}

Ancient and indigenous WH systems exist in many parts of the world and from many eras, such as contour terracing in the central highlands of Mexico (UNEP, 1983); floodwater farming in desert areas of Arizona and northern Mexico, dating back at least 1000 years (Zaunderer and Hutchinson, 1988 in Critchley and Siegert, 1991); and khadin systems in Rajasthan, India, initiated probably in the 15th century (Kolarkar et al., 1983). Reij et al. (1988) give a brief review of systems found in sub-Saharan Africa, including rock bunds and stone terraces in what is now Burkina Faso and basin systems in Mali; and Critchley and Siegert (1991) describe the 'caag' system in the Hiraan region of central Somalia.

However, the greatest wealth of ancient WH systems is probably in the Middle East.
Reviewing archaeological evidence, Prinz (1996) notes indications of WH structures in Jordan, believed to have been constructed over 9000 years ago, and in southern Mesopotamia, from $4500 \mathrm{BC}$ (Bruins et al., 1986). He continues: 'internationally, the most widely known run-off-irrigation systems have been found in the semi-arid to arid Negev desert region' (Evenari et al., 1971). Run-off agriculture in this region can be traced as far back as the 10th century $\mathrm{BC}$, when it was introduced by the inhabitants of that period (Prinz, 1996). The Negev's most productive period, however, began with the arrival of the Nabateans late in the 3rd century $\mathrm{BC}$.

Nabatean systems have also been discovered in north-western Saudi Arabia, and floodwater diversion systems, believed to be nearly 3000 years old, are still in operation today in Yemen (Brunner and Haefner, 1986) and the South Tihama area of Saudi Arabia. There is also a tradition of $\mathrm{WH}$ in northern coastal areas of Egypt, including wadi terracing and the utilization of small basins that provide natural run-on for barley cultivation (El-Naggar et al., 1988). Archaeological excavations in Libya have revealed 'structures in an area several hundred kilometers from the coast, where the mean annual precipitation is well below $50 \mathrm{~mm}$. The farming system here lasted well over 400 years and sustained a large stationary population' by producing barley, wheat, olives, grapes, figs, sheep and cattle (Prinz, 1996).

There is also a long history of $\mathrm{WH}$ in the Maghreb. In Morocco, Kutsch (1983) described highly developed 'water-concentrating' systems employed by mountain communities in the Anti-Atlas south-west of Agadir, which appear to be of ancient origin: water from mountain slopes is led by stone channels to terraces and to natural basins to support crop and tree growth in areas with a mean annual rainfall of 100-200 mm. Many different traditional systems have been recorded in Tunisia.

A large proportion of $\mathrm{WH}$ systems have fallen into disuse, and many that remain appear to be threatened. A sequence of reviews and manuals produced over the last 30 years provide a good inventory of $\mathrm{WH}$ techniques, old and new, and also essential information for their implementation (Boers and Ben-Asher, 1982; Frasier and Myer, 1983; Pacey and Cullis 1986; 
Reij et al., 1988; Critchley and Siegert, 1991; Tauer and Humborg, 1992; FAO, 1994, 2001; Prinz, 1996; Oweis et al., 1999, 2001, 2004 and Falkenmark et al., 2001). From these and other sources, one may note situations where farmers' innovations, ancient and modern, have stimulated research, and others where research has been started to solve perceived problems at the farm level. A selected sample of national experiences is summarized here to illustrate the range of experiences and potentialities.

Microcatchment WH received most research attention to obtain run-off even from light showers with minimum conveyance losses even on flat surfaces. Catchments tested have most frequently been squares of 100-250 m, feeding a basin in one corner containing a single tree (almond or pistachio). The challenge, the subject of some fairly sophisticated modelling, has been to identify the ratio between catchment and basin surface areas that gives the best compromise between evaporative losses from the basin surface and deep percolation losses below the root zone, particularly in wet years (Boers et al., 1986a,b). Conclusions from such work imply that microcatchment $\mathrm{WH}$ is not economically viable in very dry conditions, with mean annual rainfall less than $100 \mathrm{~mm}$. The problem (for economic viability) is to support a reasonably high per-hectare density of trees.

Run-off farming systems have been described by Evenari et al. (1968). Tadmor et al. (1970) report promising results from water spreading on ecotypes of 30 range species. Water harvesting in Tunisia may be divided broadly into two types: the description and rehabilitation of indigenous systems, and the large-scale technical development programme of the indigenous systems (Ennabli, 1993; Ben Mechlia and Ouessar, 2004). The meskat system, which utilizes tabias to support olive plantations, is said to cover 300,000 ha in central Tunisia (Prinz, 1996). Essentially it comprises catchments of about $500 \mathrm{~m}^{2}$ surrounded by tabia and spillways to control run-off flow into bunded plots of trees. Undoubtedly, this is a successful system, still well maintained, but Reij et al. (1988) comment that it suffers heavily from increasing land pressure, resulting in a decrease in the catchment areas, leading to lower efficiency. The jessour system is based upon the cultivation of sediments built up behind large tabia (often stone-reinforced and with stone spillways) constructed in a cascade down narrow mountain valleys in southern Tunisia. Akrimi et al. (1993), from the Institut des Regions Arides (IRA) near Medinine, reported a multidisciplinary study (technical and socioeconomic) involving jessour cultivators in the Matmata mountains.

The performance of a small run-off-basin WH system (negarim) varied from over $85 \%$ to as low as $7 \%$, depending on the size of the catchment and the root-zone storage capacity, as well as rainfall-run-off characteristics affecting deep percolation losses under a typical Mediterranean arid environment in Jordan (Oweis and Taimeh, 1996). In Yemen, focus is on the conservation of the ancient terrace system, which not only conserves soil and water but also controls water from the highest, often degraded, pasture lands down to the protection of the intensively utilized banks of the main wadis and the flood irrigation (spate irrigation) systems downstream.

In rainfed coastal areas of Egypt, the main aim was to facilitate the sedentarization of the bedouin population, and projects were taken up to rehabilitate degraded rangeland and increase run-off utilization through wadi terracing (similar to Tunisian jessours) and the enhancement of indigenous run-off farming systems (Perrier, 1988). In Pakistan, work includes WH through site-specific, land-forming techniques; storage in low-cost earthen reservoirs; and utilization as supplemental irrigation. Other work, in highland Balochistan, focuses on ways to improve the indigenous 'khuskaba' and 'sylaba' systems, where bunds are used to guide run-off water and promote infiltration (Rees et al., 1991).

\section{Components and applicability of the system}

All WH systems must have the following components:

1. Catchment area/run-off area, varying from a few square metres (microcatchment) to as large as several square kilometres (macrocatchment): the part of the land where a portion or all of the precipitation which falls on it runs off its boundaries. It can be agricultural, rocky or marginal land, or even a rooftop or a paved road. 
2. Storage facility: the place where the run-off water is held from the time it occurs until it is utilized by crops, animals, human beings and/or other uses. Storage can be: (i) above the soil surface as in surface reservoirs or ponds; (ii) in the soil profile as soil moisture; and/or (iii) underground in cisterns or as groundwater in aquifers.

3. Target or use: the beneficiary of the stored water. In agricultural production, the target is the plant or the animal, whereas in domestic use, it refers to human beings and their needs.

According to Perrier (1988), a large-scale WH system has four common elements in sequence: catchment, conveyance device, storage facility, and cultivated field. Run-off irrigation, spate irrigation, and run-off farming are among the different forms and practices that come under the umbrella of $\mathrm{WH}$.

The implementation of WH might, however, bring about a number of drawbacks such as: (i) increased soil erosion when slopes are cleared for higher run-off rates; (ii) loss of habitat of flora and fauna on those slopes; (iii) loss of habitat of flora and fauna in depressions; (iv) upstream- downstream conflicts; and (v) competition among farmers and herders.

Water harvesting is low-external-input technology, particularly advantageous in the following situations:

1. In arid and semi-arid areas where rainfall is low and unfavourably distributed, WH makes farming possible on part of the land, provided other production factors such as climate, soils and crops are favourable. Much of the economy of arid lands depends upon livestock, so it is not surprising that most of the work that has been accomplished in $\mathrm{WH}$ has been aimed at providing water for livestock. This is generally WH not requiring any pumping or input of energy for water conveyance and/or application.

2. In rainfed areas, $\mathrm{WH}$ systems can provide additional water to supplement rainfall to increase and stabilize production. Furthermore, it can alleviate the risk associated with the unpredictability of rainfall in these areas. For this case, the WH system is usually equipped with a facility (above- or underground type) to store the harvested water for later use in supplemental irrigation during drought periods (for details on supplemental irrigation see Chapter 10 , this volume).
3. In areas where public water supply for domestic and animal production is not available, inducing run-off from a treated area and storing it in a cistern or other type of reservoir for later use is a common practice in remote areas where no other water resources are available.

4. In arid lands suffering from desertification $\mathrm{WH}$ would improve the vegetative cover and can help to halt environmental degradation. Water harvesting has been found to be effective in recharging groundwater aquifers (Nasri, 2002).

Realization of the aforementioned benefits leads to many non-tangible and indirect socioeconomical benefits, such as stabilization of rural communities, reducing migration of rural inhabitants to cities, utilizing and improving local skills, and improvement of the standard of living of the millions of poor people living in the drought-stricken areas.

\section{Methods and Relevant Conditions}

\section{Classification of water-harvesting systems}

There are a dozen different classifications of $\mathrm{WH}$ techniques, and the terminology of $\mathrm{WH}$ used at the regional and international levels has not yet been standardized. The geometric configuration of $\mathrm{WH}$ systems depends upon the topography, the type of catchment treatment, the intended use and personal preference.

Water-harvesting techniques may be grouped into two categories (Table 9.1). First, techniques that directly supply run-off water from a small catchment to the crop, and thus water accumulates around the plant, infiltrates into the soil and is stored in the crop root zone. These are called microcatchment techniques, because the run-off-yielding catchments are usually small and directly adjacent to the targeted crop. The other category is macrocatchment techniques, which concentrate rainwater run-off flowing in an ephemeral wadi (natural channel) and store it in a prepared storage facility (such as a reservoir) for subsequent beneficial use. This category also includes macrocatchment techniques in which water is diverted (by proper damming or cross-structure) out of the wadi course to inundate nearby lands. 
Table 9.1. Guidelines for selecting major water harvesting systems in the drier environments (after Oweis et al., 2001).

\begin{tabular}{|c|c|c|c|c|c|c|c|c|c|}
\hline \multirow[b]{2}{*}{ Technique } & \multirow[b]{2}{*}{ Crop } & \multicolumn{2}{|c|}{ Soil } & \multicolumn{2}{|c|}{ Land } & \multicolumn{3}{|c|}{ Socio-economics } & \multirow[b]{2}{*}{ Storage type } \\
\hline & & Depth $^{a}$ & Texture & Slope ${ }^{b}$ & Stoniness $^{c}$ & Capital $^{d}$ & Laboure & Skill & \\
\hline \multicolumn{10}{|l|}{ Microcatchment } \\
\hline \multirow[t]{4}{*}{ Contour ridges } & Range & Variable & Variable & Medium, steep & Low, medium & Low & Medium & Local/training & Soil profile \\
\hline & Field & Medium, deep & Variable & Medium & Low & Low & Medium & Local/training & Soil profile \\
\hline & Trees & Deep & Medium, heavy & Low, medium & Low & Low & Medium & Local/training & Soil profile \\
\hline & Vegetable & Medium, deep & Medium, heavy & Low, medium & Low & Low & Medium & Local/training & Soil profile \\
\hline \multirow{4}{*}{$\begin{array}{l}\text { Semicircular bunds } \\
\text { (trapezoidal and } \\
\text { triangular) }\end{array}$} & Range & Medium, deep & Variable & Low, medium & Low, medium & Low & High & Local/no training & Soil profile \\
\hline & Field & Medium, deep & Medium, heavy & Low, medium & Low, medium & Low & High & Local/no training & Soil profile \\
\hline & Trees & Deep & Medium, heavy & Low, medium & Low & Low & High & Local/no training & Soil profile \\
\hline & Vegetable & Deep & Medium, heavy & Low, medium & Low & Low & High & Local/no training & Soil profile \\
\hline \multirow[t]{2}{*}{ Small pits } & Field & Deep & Medium, heavy & Low, medium & Low & Low & Medium & Local/no training & Soil profile \\
\hline & Range & Shallow, medium & Medium, heavy & Low, medium & Low, medium & Low & Medium & Local/no training & Soil profile \\
\hline \multirow[t]{2}{*}{ Small basins (Negarim) } & Range & Medium, deep & Medium, heavy & Low, medium & Low, medium & Low & High & Local/no training & Soil profile \\
\hline & Trees & Deep & Medium, heavy & Low & Low, medium & Low & High & Local/no training & Soil profile \\
\hline \multirow[t]{2}{*}{ Run-off strips } & Range & Variable & Medium, heavy & Low, medium & Low, medium & Low & Low & Local/no training & Soil profile \\
\hline & Field & Medium, deep & Medium, heavy & Low, medium & Low, medium & Low & Low & Local/no training & Soil profile \\
\hline \multirow[t]{2}{*}{ Meskat (Khushkaba) } & Trees & Deep & Medium, heavy & Low, medium & Low, medium & Low & Low & Local/no training & Soil profile \\
\hline & Field & Medium & Medium, heavy & Low, medium & Low, medium & Low & Low & Local, no training & Soil profile \\
\hline \multirow[t]{2}{*}{ Contour bench terraces } & Trees & Deep & Medium, heavy & Steep & Low, medium & High & Medium & External skill & Soil profile \\
\hline & Field & Medium & Medium, heavy & Steep & Low, medium & High & Medium & External skill & Soil profile \\
\hline \multicolumn{10}{|l|}{$\begin{array}{l}\text { Macrocatchment and } \\
\text { floodwater }\end{array}$} \\
\hline Small farm reservoirs & All crops & Variable & Medium, heavy & Low, medium & Variable & High & High & External skill & $\begin{array}{l}\text { Surface/ } \\
\quad \text { subsurface }\end{array}$ \\
\hline Wadi-bed cultivation & Trees/vegetable & Medium, deep & Medium, heavy & Low, medium & Low & Medium & Medium, high & Local & Surface/soil \\
\hline Jessour & Trees & Medium, deep & Medium, heavy & Medium, steep & Variable & Medium & High & Local/training & Surface/soil \\
\hline Water spreading & Field/trees & Medium, deep & Medium, heavy & Low, medium & Low, medium & Medium & Medium & External skill & Soil profile \\
\hline \multirow[t]{3}{*}{ Large bunds } & Trees & Deep & Medium, heavy & Low, medium & Low, medium & Medium & Medium & Local/training & Soil profile \\
\hline & Field & Medium & Medium, heavy & Low, medium & Low & Medium & Medium & Local/training & Soil profile \\
\hline & Range & Shallow, medium & Variable & Low, medium & Variable & Medium & Medium & Local/training & Soil profile \\
\hline Tanks and hafair & All crops & Variable & Medium, heavy & Low & Variable & Medium, high & Medium & External skill & $\begin{array}{l}\text { Surface/ } \\
\quad \text { subsurface }\end{array}$ \\
\hline Cisterns & $\begin{array}{l}\text { Vegetables/ } \\
\text { trees }\end{array}$ & Deep & Rock & All slopes & Variable & Medium & High & Local/training & Subsurface \\
\hline
\end{tabular}

medium \$25-100/ha, high >\$100/ha; e low <5 man-day/ha, medium 5-20 man-day/ha, high >20 man-day/ha. 
The widely used microcatchment WH techniques are contour ridges, semicircular and trapezoidal bunds, and small run-off basins. The famous zay pitting system in sub-Saharan Africa is used mainly for the cultivation of annual crops, especially cereals such as millet, maize and sorghum. A success story for microcatchment WH is reported in Box 9.1.

Macrocatchment systems are characterized by having run-off water collected from relatively large catchments. Often the catchments are natural rangeland or a mountainous area. Catchments for these systems are mostly located outside farm boundaries, where individual farmers have little or no control over them. Harvested run-off may be stored in the soil profile for direct use by the crop, in aquifers as a recharge system or in a storage facility ranging from an on-farm pond or tank to a small dam constructed across the wadi, and used later for domestic purpose, livestock and supplemental irrigation. Several issues, both technical and socio-economic, need to be considered for optimal implementation of this WH system. Two success stories for macrocatchment $\mathrm{WH}$ are reported in Box 9.2 and Box 9.3.

\section{Constraints to adoption}

- The difficulties due to farmers' unfamiliarity with the technology.

- Conflicts and disputes on water rights, land ownership and use.

- Lack of adequate characterization of rainfall, evapotranspiration and soil properties.

- Risk of crop failure in drought years may severely hit the poor.

- Weak institutions and lack of policies that deal with conjugate use of green and blue waters.

Microcatchment systems are usually within an individual farm perimeter. This is a simple and low-cost approach, although farmers may experience some difficulty with elements requiring precision, such as following the contour lines or determining maximum slope. The community may be involved in micro- and macrocatchment WH systems, typically through a careful locally planned programme such as the community watershed programme in India (Joshi et al., 2005; Chapter 1, this volume). Ideally, these should be planned at the watershed level with farmers' participation in their planning. Community-based management, farmer participation in planning and cost sharing, or the

Box 9.1. Small run-off-harvesting basins for fruit trees in Jordan.

The arid land of Jordan is of Mediterranean climate, with a mean annual rainfall of 100-200 mm, which occurs mainly in the cold winter, from December to March. Long, hot and dry summers make rainfed agriculture uneconomic. Farmers in the area depend on livestock using poor natural vegetation and limited groundwater for domestic use. There are no fruit trees without irrigation in this zone. In 1987, a project was launched by the University of Jordan to diversify farmers' production by introducing tree crops using additional water from a microcatchment water-harvesting system. The negarim (small diamond basins) system with plots of 50-100 $\mathrm{m}^{2}$ was constructed on deep soils (see figure below). Almonds and olive trees were planted in the winter season. Polymers were added to the planting pit to increase soil water storage capacity to sustain the long dry summer.

Trees planted survived the drought and grew satisfactorily over the seasons and are still producing after 23 years. Farmers adopted the technology in several areas of the dry zone. Although the intervention was very successful, there were some problems. The selection of deep soils and drought-tolerant species are so critical in this area. The soil should be deep enough to hold sufficient water to sustain the plant for the whole dry season. It is important that the crop is tolerant to drought so that the trees do not die after some years, even if drought occurs.

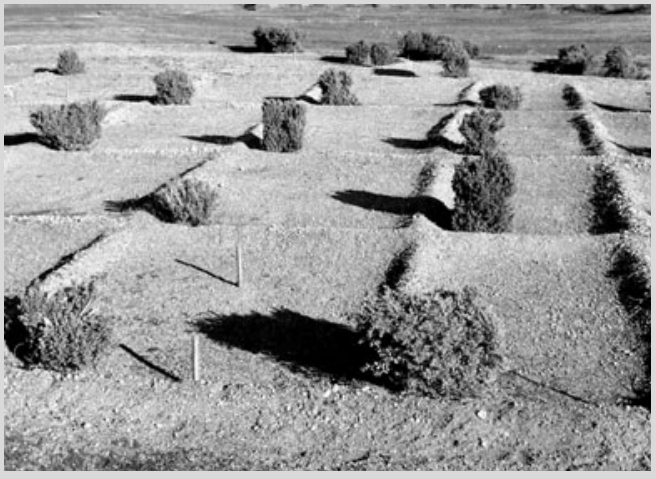

The negarim (small basin) water-harvesting system. 
Box 9.2. Cisterns in north-western Egypt.

Cisterns are ancient, indigenous rainwater-harvesting systems, used mainly for supplying human and animal water needs in water-scarce areas. They are usually subsurface reservoirs, with capacity ranging from 10 to $500 \mathrm{~m}^{3}$. Along the north-west coast of Egypt, with an average annual rainfall of about $150 \mathrm{~mm}$, no other source of freshwater exists. Run-off resulting from a few major rainstorms in winter is directed into cisterns from adjacent catchments or through channels from remote areas. The run-off from the first rainfall event of a season is usually diverted away from the cistern to reduce the likelihood of pollution. Settling basins are also provided at the cistern entrance. A bucket and a rope are typically used to lift water.

Farmers in north-western Egypt dig large cisterns (200-300 $\left.\mathrm{m}^{3}\right)$ in the earth deposits underneath a layer of solid rock (see figure below). Modern concrete cisterns are now being constructed in places where there is no such rocky layer. Water is used not only for human and animal needs but also for growing cash crops in home gardens.

However, traditional cisterns require a large catchment area, having small capacity, with high construction cost and maintenance. A project to deal with these issues and to provide technical and financial support to the local communities was initiated in 1998. Three interventions were found to substantially improve the system efficiency:

1. Clearing, cleaning and smoothing of the catchment area substantially improved the run-off efficiency and water quality.

2. The cistern's seasonal water capacity was more than tripled through efficient management, without increasing its actual size and cost. Hydrological studies showed that the cistern could be re-filled at least three times during the rainy season. Farmers were encouraged to use the water from the first and second filling directly for agriculture, and to preserve the third filling for human and animal consumption during the summer. The availability of manual pumps and low-cost pipes helped to make the task easier.

3. The water use efficiency was improved by providing a small kit of materials and introducing a few changes in the agricultural production system at the homegarden level. For example, placing high-value crops such as seedlings and vegetables in plastic houses became popular and provided additional income to the farmers, with little additional water.

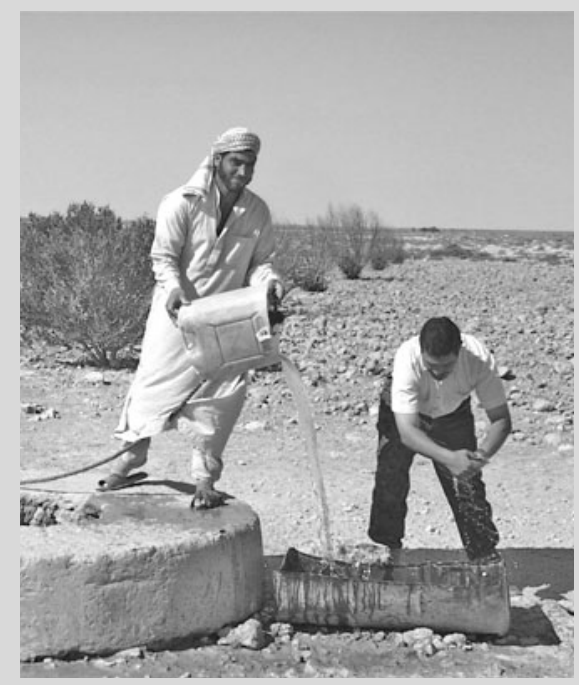

Cistern in northern Egypt. establishment of a cooperative can be among alternatives recommended to manage these reservoirs and to overcome the problem of smallholdings (Wani et al., 2008). A successful system, however, must be technically sound, properly designed and maintained, economically feasible, and capable of being integrated into the social traditions and abilities of the users.

\section{Potential in arid and semi-arid regions}

Improvement of agricultural productivity in the dry areas goes through the development of land management practices. Water harvesting is thus based on the dryland management principle that aims to deprive part of the land of its low and unproductive share of rain in order to add it to another part of the land and obtain economic yields (Oweis et al., 2001). Successful implementation of $\mathrm{WH}$ practices requires significant knowledge input from hydrology, agronomy and sociology. Data on rainfall, soil and relief, as well as information on the cropping systems and the local socio-economic conditions, are all needed. Identification of areas suitable for $\mathrm{WH}$ practices is crucial for successful development of $\mathrm{WH}$. Because $\mathrm{WH}$ deals with large areas, the cost of surveys and analysis could be prohibitive 
Box 9.3. Small farm reservoirs in Jordan.

Farmers in the dry areas store water collected during the rainy winter for later use, either in the same season or in the following dry season. This practice is useful in rainfed areas where rain is not sufficient to support rainfed crops in winter and/or when the water is needed for domestic or livestock use.

Three small earth dams, in a typical area of the Jordan steppe (Muaqqar), were built across a wadi, creating small farm reservoirs of 10,000-20,000 $\mathrm{m}^{3}$ (see figure below). The reservoirs' water has been used to irrigate field crops and trees and support livestock for over 20 years. Evaluation of run-off adequacy, proper dam construction, adequacy of spillway, siltation and the consequences downstream are major issues. The experience revealed the following prerequisites for success:

1. Water is required for multiple uses, such as for drinking, livestock or environmental purposes.

2. Adequate and sustainable run-off is available. Potential upstream development may reduce run-off amounts downstream.

3. Farmers' capacity to manage the facility.

4. Water rights and requirements of other uses are considered.

Large numbers of smaller-size reservoirs distributed over the catchment area have real advantages in water savings, social equity and environmental impact. The commonly practised method of delaying the use of water stored from winter to summer may not be the best strategy. To maximize the benefits, it is generally recommended that water be transferred from the reservoir and be stored in the soil as soon as possible. Storing reservoir water in the soil profile for direct use by crops in the winter season saves substantial evaporation losses that normally occur during the high evaporative demand period. Emptying the reservoir early in the winter provides more capacity for other run-off events. Furthermore, higher reservoir water use efficiency can be achieved by supplemental irrigation of winter crops over full irrigation of summer crops.

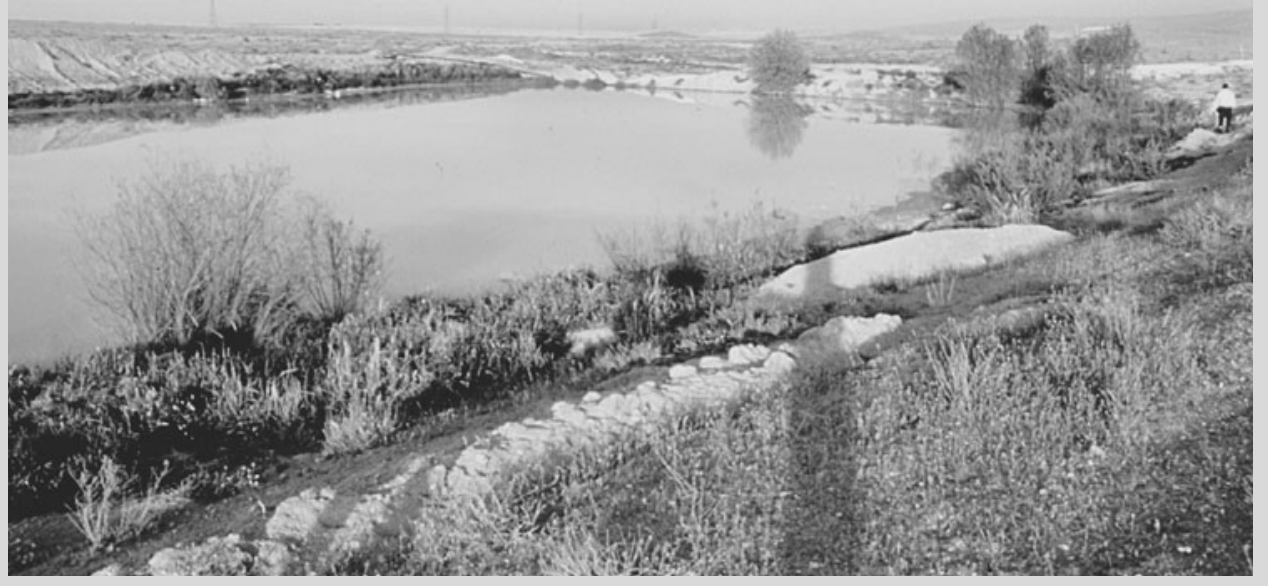

Small farm reservoir in Jordan steppe.

for carrying out the necessary work. Low-cost methods for assessing the potential of $\mathrm{WH}$ are of greatest interest to stakeholders and investment agencies.

Satellite and remote-sensing technologies coupled with geographical information systems (GIS) are the most powerful and reasonably cost-efficient methods/tools that help in assessing the potential of $\mathrm{WH}$. The principal steps used to analyse remotely sensed data to identify suitable areas for $\mathrm{WH}$ include: (i) definition of data needs, e.g. land use, geology, pedology, hydrology, etc.; (ii) data collection using remote sensing and other techniques; (iii) data analysis, e.g. measurement, classification and estimation analysis; (iv) verification of the analysis results; and $(\mathrm{v})$ presenting the results in a suitable format, such as maps, computer data file, written reports with diagrams, tables, maps, etc.

In this section summaries of two cases, one in Syria and another in Tunisia, for assessing the potential of WH in WANA are presented. 


\section{The case of Syria}

The assessment was taken up by matching, in a GIS environment, simple biophysical information, systematically available at country level, to the broad requirements of the specified WH systems (De Pauw et al., 2008). The systems evaluated include 13 microcatchment systems, based on combinations of six techniques and three crop groups, and one generalized macrocatchment system. The main microcatchment techniques for which a suitability assessment can be applied at the level of Syria are: contour ridges, semicircular and trapezoidal bunds, small pits, small run-off basins, run-off strips, inter-row systems and contour-bench terraces. Three crop groups (rangeland, field crops and fruit trees) were considered.

The environmental criteria for suitability were based on expert guidelines for selecting $\mathrm{WH}$ techniques in the drier environments (Oweis et al., 2001). They included precipitation, slope, and soil depth, texture and salinity, as well as land use/land cover and geological substratum.
The data set included interpolated surfaces of mean annual precipitation, the SRTM digital elevation model, a soil map of Syria, a land use/land cover map of Syria and a geological map of Syria.

The results of the suitability assessments are presented as a set of 14 maps and summarized at provincial and district level in the form of tables. As a sample output, Figs 9.1 and 9.2 show the suitability of contour ridges for range shrubs and small run-off basins for tree crops, respectively, in Syria (De Pauw et al., 2008). Validation by comparing the results predicted by the model with an assessment of actual conditions in sample locations is required.

\section{The case of Tunisia}

A work aimed at developing a methodology for the assessment of land suitability for $\mathrm{WH}$ systems was carried out under the Comprehensive Assessment initiative. Available data and knowledge were used together with modern tools such as image processing and GIS to map the

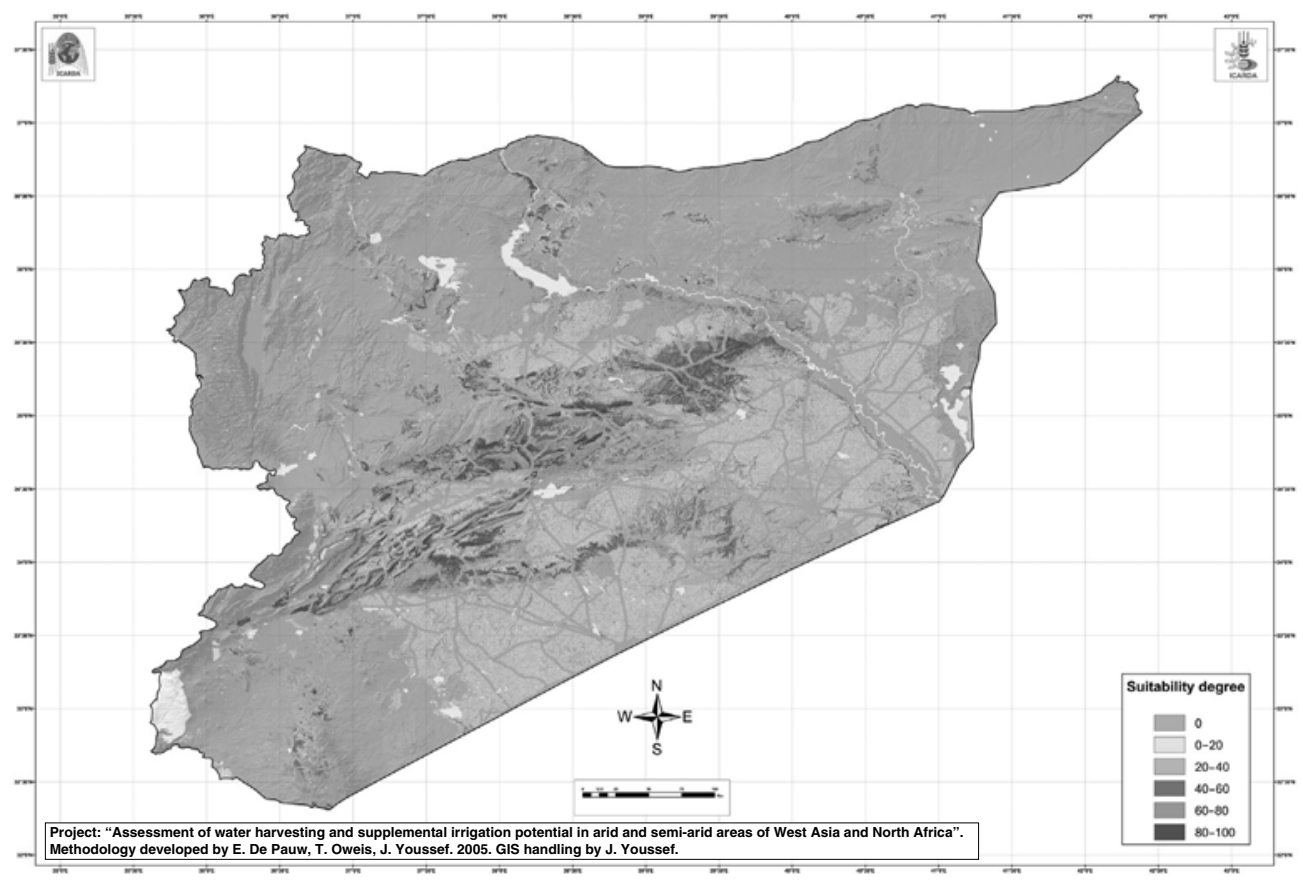

Fig. 9.1. Suitability of contour ridges microcatchment water harvesting for range shrubs in Syria (Source: De Pauw et al., 2008). 


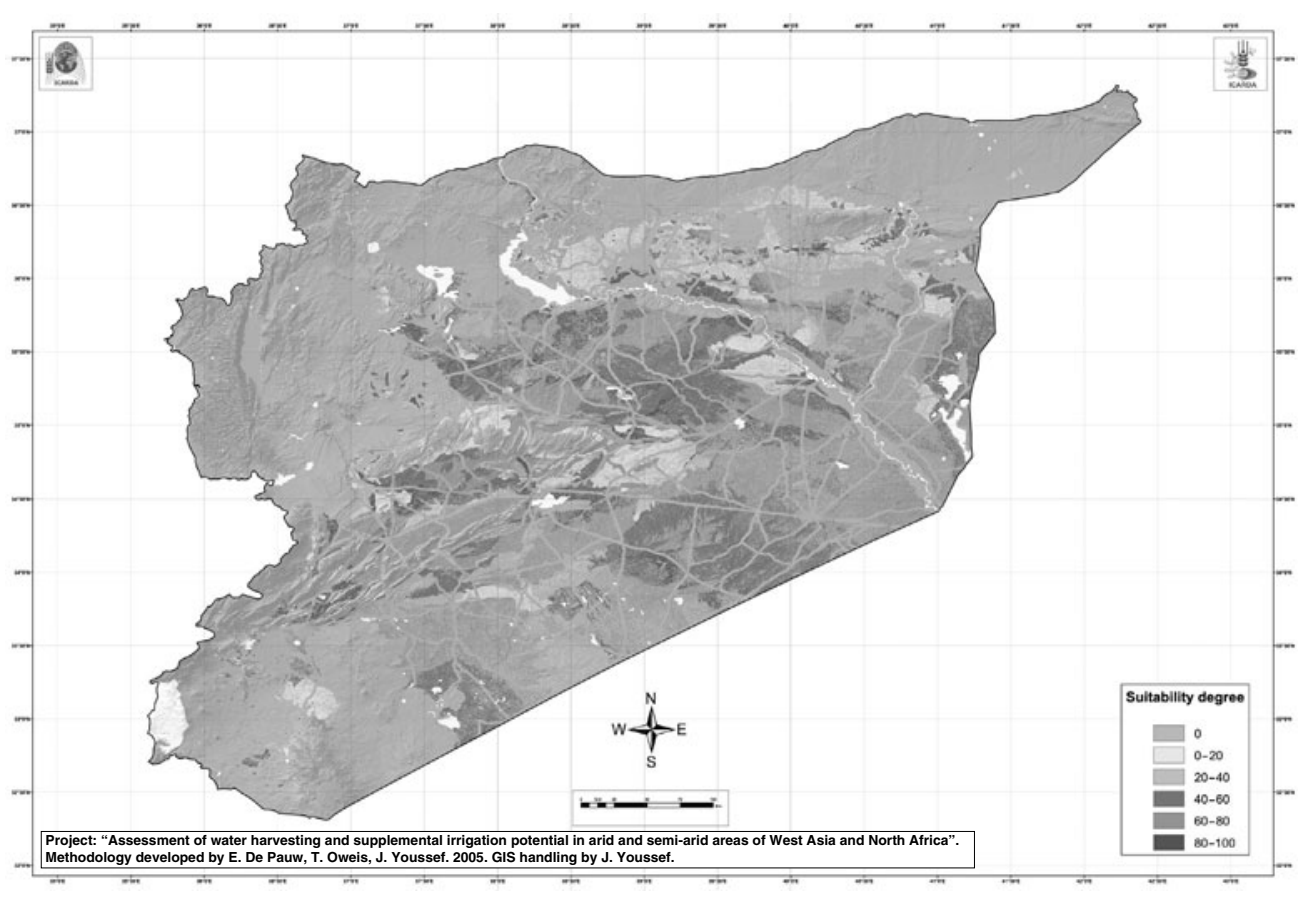

Fig. 9.2. Suitability of small run-off basins microcatchment water harvesting for tree crops in Syria (Source: De Pauw et al., 2008).

potential for $\mathrm{WH}$ at a large scale. It took advantage of the available experiences in various areas of the region but particularly in Tunisia.

The work is concentrated in the arid region of southern Tunisia, where annual rainfall is less than $250 \mathrm{~mm}$. Understanding of social factors is a prerequisite to any successful implementation of WH systems; therefore, a spatial integration of socio-economic data has been made in the study. There is a common agreement that whatever the soil and water conservation measures are they must first of all support a positive economic alternative to existing conditions in order to get farmers' acceptance.

The number of practices involving the use of run-off water to supplement rainfall deficiencies is quite large. There are probably more than 25 techniques in Tunisia. They vary according to a multitude of parameters but all attempt to optimize the use of available water, soil and biological resources. To make the best use of run-off water, characteristics such as rooting system, drought and flood resistance are important criteria for fruit trees, but for annual crops the critical issue is how to optimize growth duration in relation to water supply.

Jessour and tabia are widely practised in Tunisia and are mainly used for growing trees and annual crops (Fig. 9.3). These WH structures are situated in gullies or in wadi tributaries to form deep and adequate soil substratum, collected from erosion of upstream contributing areas. For reasons of practicality, the selected systems were limited to the jessour and tabia techniques, which are widely used in the mountainous area of southern Tunisia, where annual rainfall is below $250 \mathrm{~mm}$ (Ben Mechlia et al., 2006).

In southern Tunisia, jessour structures are used with a slope range of $2.7-25 \%$ to collect water from a watershed area of 100 ha. In areas with slope of $1-2.7 \%$, larger watersheds (370 ha) are needed in order to generate enough run-off water to support long-term farming with the tabia system. Farmers are involved in all subsequent stages of the work, alongside the researchers, identifying, testing and eventually demonstrating successful new techniques. 


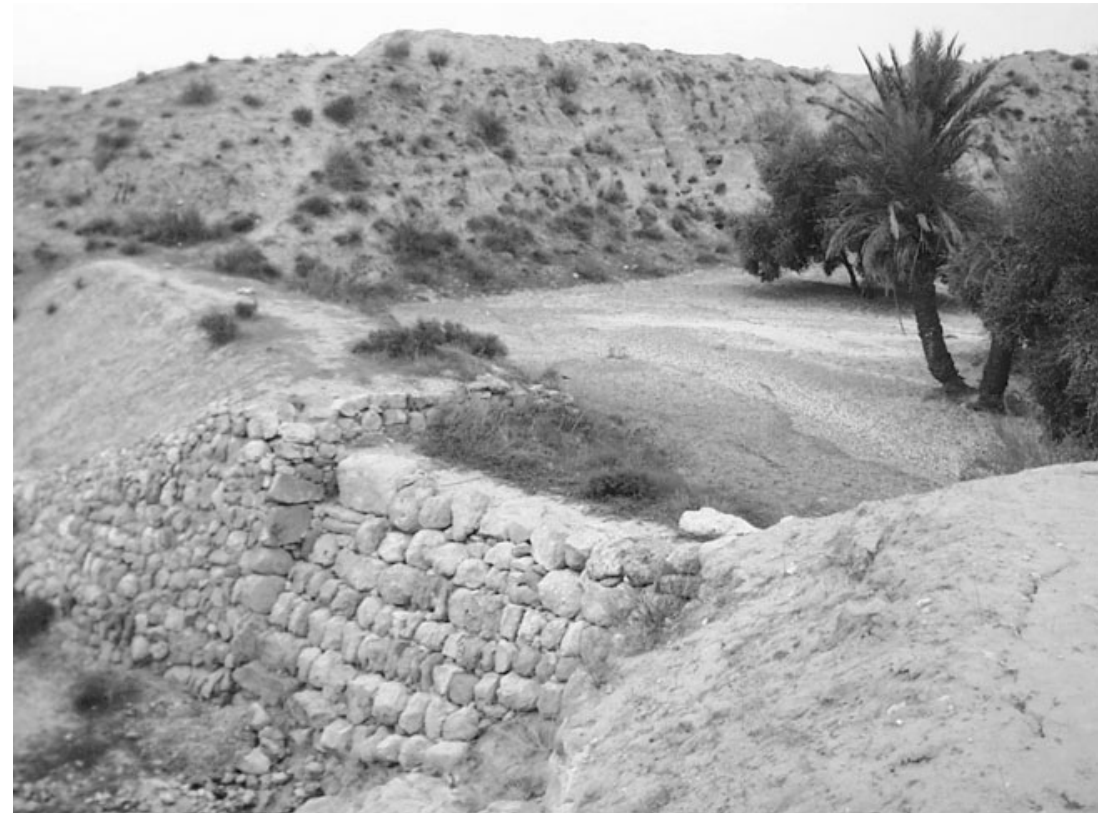

Fig. 9.3. Jessours are widely practised in Tunisia for water harvesting.

\section{Economics of Water Harvesting}

\section{Direct versus indirect benefits}

Most of the available work on WH deals with technical, agronomical and social aspects of this practice; however, few and inconclusive assessments are available on the economical feasibility of $\mathrm{WH}$ in the drier environments. In India, detailed meta-analysis of watershed programmes has documented the benefits of $\mathrm{WH}$, including economic parameters such as benefit-cost ratios and internal rate of returns (for details see Chapter 14, this volume). However, benefits of $\mathrm{WH}$ in these environments include, in addition to food and feed production (direct benefits), substantial environmental and social returns, such as combating land degradation and migration from rural to urban areas and employment. Methodologies for evaluating indirect benefits are sometimes controversial and the private sector is often not interested in these benefits. Economic assessment of macrocatchments $\mathrm{WH}$ is more complicated because of the upstream-downstream interactions in addition to social and environmental issues.

\section{Microcatchments for field crops}

In arid and semi-arid regions, limited water availability and soil fertility, in almost all cases, are the major constraints to dry farming. It is generally recognized that $\mathrm{WH}$ can significantly increase crop yields in such areas. The economic feasibility of microcatchment WH depends on the following interrelated issues:

1. Whether or not the cropped area under WH yields more than that of the total area (cropped and catchment) under purely rainfed conditions (i.e. no $\mathrm{WH}$ intervention). For example, if the catchment area to the cropped area ratio is $1: 1$, is the net return of the cropped area more than that of the purely rainfed part of the total area without $\mathrm{WH}$ intervention? This would require that the yield in the cropped area should be at least twice that of purely rainfed area. The assumption here is that the catchment area is cultivable. The rationale behind this question is that there is an opportunity cost for the catchment land, which could be used to grow crops instead of catching water. This is particularly true in the case of microcatchment $\mathrm{WH}$ under limited suitable arable land. 
2. The differences in the fixed and variable costs associated with the proportions of the crop and catchment areas play a role because a smaller cropped area needs less seed and fertilizers (if any) and probably less labour for preparation.

3. Whether there is an increase in the price of outputs relative to the costs of inputs or a decrease in the cost of inputs relative to the price of outputs. This depends on market dynamics.

With these issues in mind, a 6-year economical and viability assessment of $\mathrm{WH}$ for wheat and barley in the farmers' fields of highland Balochistan (Pakistan), where total seasonal rainfall ranges between 96 and $282 \mathrm{~mm}$, was conducted and it revealed the following (Rodriguez et al., 1996):

1. Water harvesting is a low-cost method of generating run-off and increasing yield, in some cases up to threefold. Wheat is more responsive to water availability than barley. However, if the yield is adjusted to the total area (cropped plus catchment areas), it becomes less than the yield of the control (i.e. the whole area cropped under rainfed conditions) in most cases.

2. The increase in wheat yield (biomass) per unit cropped area is more pronounced in the drier years. For example, the yield is increased by $180 \%$ and $80 \%$ under seasonal rainfall of $102 \mathrm{~mm}$ and $282 \mathrm{~mm}$, respectively.

3. For wheat, the ratio of catchment area to cropped area of 1:1 (i.e. one-half of the area used for water catchment and one-half for planting) had $23 \%$ higher net benefits than the control and decreased the variation in income by $19 \%$. Thus, WH has positive effects on both stability and income, which are vital to wheat growers in very marginal areas. For barley, the $1: 1$ area ratio fields yielded $25 \%$ lower net benefits than the control and increased variation in net benefits by $4 \%$.

4. Due to waterlogging, however, for wheat the $2: 1$ area ratio fields had a $29 \%$ lower net benefit than the control, but the variation in net benefits was reduced by $8 \%$. For barley the $2: 1$ area ratio had $36 \%$ lower net benefits than the control and $18 \%$ more variation. To overcome this problem, it is suggested that the crops are grown in broad beds, with furrows at 1-2 m intervals, where the run-off water could be collected.

\section{Macrocatchments in sub-Saharan Africa}

A second case study for economic assessment of $\mathrm{WH}$ is from Africa. Rainwater harvesting (RWH) is being widely promoted as a way to improve the production of crops and livestock in semi-arid areas of eastern and Southern Africa. However, evidence of the performance of RWH with respect to food and income security, and thus reduction of poverty, is limited and far apart. In Tanzania, farmers are using RWH technology to produce maize, paddy and vegetables in semi-arid areas where it would otherwise be impossible or very difficult to produce (Hatibu et al., 2006). The economics of these practices are analysed in two contrasting districts over a period of 5 years. Gross margin analyses were used to assess the economic performance of different rainwater-capturing systems with respect to return to labour and thus income generation. It then provides an analysis of the priority actions needed to enhance the performance of RWH in the semi-arid areas of the region. The evaluated $\mathrm{WH}$ systems included microcatchment and macrocatchment with floodwater diversion and small storage ponds.

Results show that most farmers have invested heavily in terms of labour to establish and maintain earth structures for the capture of run-off without corresponding investment in nutrient management, leading to low yields for the cereal enterprises. When this is coupled with low farmgate prices, the improvements of RWH for cereal systems did not lead to a corresponding increase in returns to labour for the majority. However, high returns of US\$10-200/person/day were obtained when RWH was applied to vegetable enterprises. Therefore, for RWH to contribute to improved incomes and food security, smallholder farmers should be assisted to change from subsistent to commercial objectives with market-oriented production of high-value crops combined with processing into value-added products. This will require farmers to participate in food markets and thus increasingly depend on the market for food security as opposed to emphasizing self-sufficiency at the household level.

Yuan et al. (2003) evaluated the economic feasibility of agriculture with RWH and supplemental irrigation in a semi-arid region. The 
results show the importance of making full use of every open-air hardened surface to collect rainwater and to establish rainwater catchment areas by utilizing unoccupied land. The results also show that the usefulness of the harvested rainwater is enhanced when water-saving and seepage-prevention techniques are employed. The results indicate that in order to maximize investment it is essential to select crops with a water requirement process that coincides with local rainfall events. Potato was found to be the most suitable crop in the studied region. The economic indices for potato were superior to spring wheat, maize and wheat/maize intercropping. Therefore, potato production using RWH and supplemental irrigation is the best alternative for cropping systems in the semi-arid region of Gansu, China.

\section{Water Harvesting for Supplemental Irrigation}

In Kenya (Machakos district) and Burkina Faso (Ouagouya), there is significant scope for improving water productivity in rainfed farming through supplemental irrigation, especially if combined with soil fertility management. Surface run-off from small catchments (1-2 ha) was harvested and stored in manually dug farm ponds (100-250 $\mathrm{m}^{3}$ storage capacity). Simple gravityfed furrow irrigation was used. During the three and five experimental rainy seasons in Burkina Faso (mono-modal rain pattern) and Kenya (bimodal rain pattern), respectively, supplemental irrigation amounted, on average, to $70 \mathrm{~mm}$ per growing season with a range of $20-220 \mathrm{~mm}$. Seasonal rainfall ranged from 196 to $557 \mathrm{~mm}$ in Kenya and 418 to $667 \mathrm{~mm}$ in Burkina Faso. In Kenya, one rainy season was classified as a meteorological drought (short rains of 1998/99), resulting in complete crop failure, while one season at each site (long rains of 2000 in Kenya and the rainy season 2000 in Burkina Faso) resulted in complete crop failure for most neighbouring farmers, but the WH system enabled the harvest of an above-average yield ( $>1 \mathrm{t} / \mathrm{ha})$. The highest improvement in yield and water use efficiency was achieved by combining supplemental irrigation and fertilizer application (for details on supplemental irrigation see Chapter 10, this volume). Interestingly, in both the locations, fertilizer application alone (in Kenya with low application of $30 \mathrm{~kg}$ nitrogen/ha and high application of $80 \mathrm{~kg}$ nitrogen/ha) resulted in higher average yield and water use efficiency than $\mathrm{WH}$ alone during years with gentle dry spells (for seasons with severe dry spells, e.g. long rains of 2000 in Kenya, non-irrigated crop resulted in complete crop failure). Nevertheless, it indicates that the full benefits of $\mathrm{WH}$ for supplemental irrigation can only be met by simultaneously addressing soil fertility management (Rockström et al., 2001).

For resource-poor smallholder farmers in water-scarce areas, even small volumes of stored water for supplemental irrigation can significantly improve the household economy. In Gansu Province in China, small (10-60 $\mathrm{m}^{3}$; $30 \mathrm{~m}^{3}$ on average) subsurface storage tanks are promoted on a large scale. These tanks collect surface run-off from small, often treated catchments (e.g. with asphalt or concrete). Research using these subsurface tanks for supplemental irrigation of wheat in several counties in Gansu Province (Li et al., 2000) indicated a $20 \%$ increase in water use efficiency (rain amounting to $420 \mathrm{~mm}+$ supplemental irrigation ranging from 35 to $105 \mathrm{~mm}$ ). Water use efficiency increased on average from 8.7 $\mathrm{kg} / \mathrm{mm} / \mathrm{ha}$ for rainfed wheat to $10.3 \mathrm{~kg} / \mathrm{mm} / \mathrm{ha}$ for wheat receiving supplemental irrigation. Incremental water use efficiency ranged from 17 to $30 \mathrm{~kg} / \mathrm{mm} / \mathrm{ha}$, indicating the large relative added value of supplemental irrigation. Similar results were observed in maize, with yield increases of $20-88 \%$, and incremental water use efficiencies ranging from 15 to 62 $\mathrm{kg} / \mathrm{mm} / \mathrm{ha}$ of supplemental irrigation (Li et al., 2000).

Benefiting from the Chinese experience with subsurface tanks, similar systems are at present being developed and promoted in Kenya and Ethiopia. In Kenya (Machakos district) these tanks are used to irrigate kitchen gardens and enable farmers to diversify sources of income from the land. The micro-irrigation schemes are promoted together with commercially available low-pressure drip-irrigation systems. Cheap drip kits (e.g. the Chapin bucket kit) save water and labour, and are increasingly adopted among farmers, e.g. in Kenya. Combining WH with drip irrigation can result in very significant waterproductivity improvements. 
Evaporation and seepage losses and silting are major problems of storage reservoirs. It is important to minimize the adverse effects of these problems in the design of a surface-water storage facility. Silting may be minimized by arresting the silt and sand on the catchment area itself, mainly through controlling catchment erosion but also by installing silt-traps. Seepage can be minimized by careful site selection, avoiding sand, gravel and highly permeable soils, or by compaction of the reservoir bottom and sides. Other than minimizing the water surface area, there is no costeffective way of eliminating evaporation losses from open water bodies. Therefore, to use collected run-off water more efficiently, it is highly recommended to apply this water to the cropped area as soon as it is needed as supplemental irrigation.

Investing in storage facilities, among other opportunities, seems promising in the drier environments. Other opportunities are related to manufacturing and production of low-cost and environment-friendly materials and implements for surface run-off inducement (Box 9.4). This may include material and techniques to reduce evaporation and seepage losses. Opportunities may also include the production of low-cost materials and/or additives, such as polymers, that could be added to and mixed with the soil of the cropped area to increase its water-holding capacity, especially in the case of light and/or shallow soils.

\section{Combating Desertification with Water Harvesting}

Rangelands in the dry areas are a very fragile ecosystem. They receive inadequate annual rainfall for economical dry farming. Natural vegetation and plants undergo severe moisturestress periods, which significantly reduce growth and result in very poor vegetative cover. Part of the rain which flows as run-off usually forms erosive streams and results in severe soil

Box 9.4. Rehabilitation of rangelands in Syria.

The Syrian Badia (rangeland) consists of about 55\% of the total area of the country, with an average annual rainfall of less than $200 \mathrm{~mm}$. Livestock-based production systems in this area provide about two-thirds of the red meat and one-third of the milk production of the country. Natural vegetation is an important source of feed for the livestock. The Badia production system is very fragile and degraded because of high spatial and temporal variation of rainfall, overgrazing and low vegetation regeneration and lack of appropriate rainwater management. Water harvesting is an efficient tool to improve soil-moisture storage and shrub establishment.

In 1995, a project was launched to rehabilitate an area of about 36,000 ha through integrating microcatchment water-harvesting techniques for sustainable biomass production (Somme et al., 2004). Two runoff water-harvesting sites were developed for evaluation; one site was developed by manual construction of semicircular bunds, while the other with mechanically built contour ridges. A suitable area was kept untreated as a control. Atriplex halimus and Salsola vermiculata shrubs were planted.

The water-harvesting system managed to mitigate the effect of drought and rainfall variation in the drier environments, as indicated by the significant increase in the shrub survival rates (see table below). The shrub survival rate was increased from about $3 \%$ to about $90 \%$ by using water harvesting. The limited surviving shrubs on the control died during the first year of drought. Shrubs supported with water-harvesting bunds survived the 3 consecutive drought years and are still growing vigorously. The assessed interventions are simple to construct and maintain even by small-scale farmers.

Shrub survival rate (\% by number) for the semicircular bunds of 2, 4 and $6 \mathrm{~m}$ diameter in the Syrian Badia (rangeland). (Source: Somme et al., 2004).

\begin{tabular}{|c|c|c|c|c|c|c|c|c|c|}
\hline \multirow[b]{2}{*}{ Year } & \multirow{2}{*}{$\begin{array}{l}\text { Rainfall } \\
(\mathrm{mm})\end{array}$} & \multirow{2}{*}{$\begin{array}{l}\text { No. of } \\
\text { bunds }\end{array}$} & \multicolumn{3}{|c|}{ Land slope $2 \%$} & \multirow{2}{*}{$\begin{array}{l}\text { No. of } \\
\text { bunds }\end{array}$} & \multicolumn{3}{|c|}{ Land slope $5 \%$} \\
\hline & & & $2 m$ & $4 \mathrm{~m}$ & $6 \mathrm{~m}$ & & $2 \mathrm{~m}$ & $4 \mathrm{~m}$ & $6 \mathrm{~m}$ \\
\hline $1997 / 98$ & 174 & 23 & 74 & 75 & 70 & 20 & 96 & 98 & 97 \\
\hline $1998 / 99$ & 36 & 12 & 52 & 54 & 51 & 7 & 92 & 95 & 93 \\
\hline $1999 / 00$ & 42 & 5 & 28 & 30 & 22 & 2 & 92 & 93 & 89 \\
\hline
\end{tabular}


erosion and land degradation. Increasing consumer demand for sheep, meat and milk, in combination with rapid population growth and inappropriate government policies, have stimulated a substantial increase in the livestock population.

Water harvesting can improve the vegetative cover, increase the carrying grazing capacity of rangeland and help halt environmental degradation (Fig. 9.4). It can be an individual or community response to an environmental limitation. Practices of rainwater harvesting provide a sound basis for improved resources management, reduce cost and provide people with tools for improving the rangelands and, hence, their income and livelihoods (Box 9.4).

Land tenure in rangelands is a major constraint to development and varies from one country to the other. In Syria, for example, rangeland is largely public land, but other forms of land tenure such as rented and private land ownership also exist. In Jordan, however, most of the rangeland is private tribal lands. Owing to lack of appropriate land tenure systems in most of the dry countries, communal land is used as common property, where overgrazing is a common practice and little attention is given to sustainability.

Although rainfall is generally higher in the mountainous areas, they have problems of accessibility and marginalized poor communities. The complex landscape consists of steep slopes, terraced croplands, sloping rangelands and scattered patches of shrubs and trees. Most of the agriculture in the area depends on direct rainfall, and irrigated agriculture takes place along the banks of the wadis that dissect the mountains. The main cause of land degradation here is due to water erosion.

The degradation of the indigenous terraces in the Yemeni mountains is well known and documented. Poor maintenance and improper run-off management are believed to be the major sources of soil erosion that occurs as the result of successive failure of these terraces, which require a high annual maintenance cost. Steep topography, coupled with relatively high rainfall, is another factor that, in the absence of appropriate measures for sustainable natural resource management, contributes to soil erosion and other types of land degradation.

Considerable progress has been made in identifying efficient $\mathrm{WH}$ and use schemes for both crop production and combating desertification. Constraints to the implementation and adaptation of these schemes include farmers' unfamiliarity with the technology; conflicts and disputes on water rights, land ownership and use; and lack of adequate characterization of rainfall, evapotranspiration and soil properties.

One of the crucial social aspects for the success is the involvement/participation of the stakeholders or beneficiaries. All stakeholders have to get involved in planning, designing and implementation of $\mathrm{WH}$ structures. A consensus is necessary for operation and maintenance of these structures. Involvement of local NGOs (non-governmental organizations) may also benefit the community for collective action. (a)

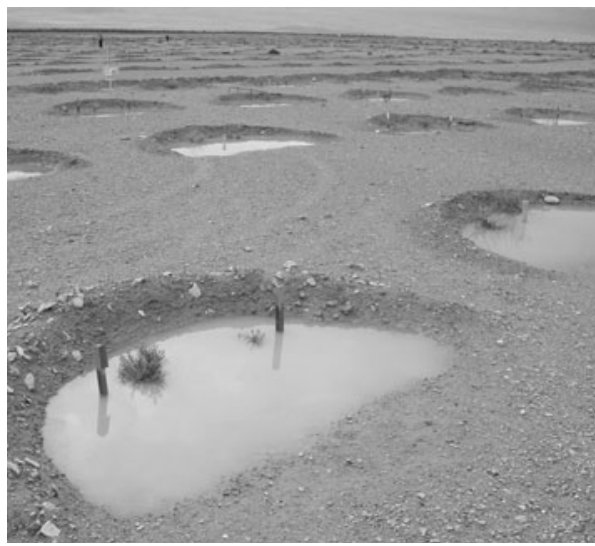

(b)

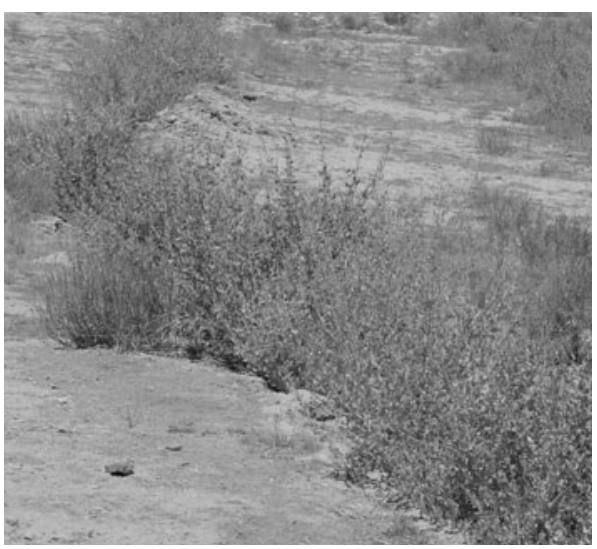

Fig. 9.4. Manually developed semicircular bunds: (a) field plot and shrub after 2 years showing water harvested after a storm; (b) field plot and shrub after 4 years. 


\section{Conclusions}

Water harvesting is one option that increases the amount of water per unit cropping area, reduces drought impact and enables the use of run-off beneficially. It is low-external-input technology that makes farming possible on part of the land, provided other production factors such as climate, soils and crops are favourable. In arid lands suffering from desertification, WH would improve the vegetative cover and can help to halt environmental degradation. Water harvesting has been found to be effective in recharging groundwater aquifers. Non-tangible and indirect socio-economic benefits, such as combating land degradation, stabilization of rural communities, reducing migration of rural inhabitants to cities, utilizing and improving local skills, and improvement of the standard of living of the millions of poor people living in the dry areas, should be taken into consideration when conducting $\mathrm{WH}$ economic and feasibility studies.

Successful implementation of WH practices requires significant knowledge input from hydrology, agronomy and sociology. Identification of areas suitable for $\mathrm{WH}$ practices is crucial for successful development of WH. Low-cost methods for assessing the potential of $\mathrm{WH}$ are needed and they are of greatest interest to stakeholders and investment agencies. Rainwater harvesting should suit its purpose, be accepted by the local population and be sustainable in the local environment. The decision-making process concerning the best method applicable in particular environmental and geophysical conditions depends on the kind of crop to be grown and prevalent socio-economic and cultural factors. Local availability of labour and materials are the most important factors. The accessibility of the site and distance from the village have also to be considered for construction of $\mathrm{WH}$ structures. One of the crucial social aspects for the success is the involvement/participation of the stakeholders or beneficiaries. All stakeholders have to get involved in planning, designing and implementation of $\mathrm{WH}$ structures.

The implementation of $\mathrm{WH}$, however, requires taking care of possible drawbacks such as: (i) increased soil erosion and loss of habitat of flora and fauna in macrocatchments; (ii) upstream-downstream conflicts; and (iii) competition among farmers and herders.

\section{References}

Akrimi, N., Neffati, M., Taamallah, H. and Sghaier, M. (1993) Resource management in the Graguer basin of southern Tunisia. In: Proceedings of Workshop on Dryland Resource Management and the Improvement of Rainfed Agriculture in the Drier Areas of West Asia and North Africa. International Center for Agricultural Research in the Dry Areas (ICARDA), Aleppo, Syria.

Ben Mechlia, N. and Ouessar, M. (2004) Water harvesting systems in Tunisia. In: Oweis, T., Hachum, A., Bruggeman, A. (eds) Indigenous Water Harvesting Systems in West Asia and North Africa. International Center for Agricultural Research in the Dry Areas (ICARDA), Aleppo, Syria, pp. 19-41.

Ben Mechlia, N., Oweis, T., Masmoudi, M., Khattali, H., Ouessar, M., Sghaier, M., Bruggeman, A. and Anane, M. (2006) Assessment of water harvesting potential in arid areas: methodology and a case study from Tunisia. The Comprehensive Assessment of Water Management in Agriculture, Research Report. International Center for Agricultural Research in the Dry Areas (ICARDA), Aleppo, Syria.

Boers, T.M. and Ben-Asher, J. (1982) A review of rainwater harvesting. Agricultural Water Management 5 , $145-158$.

Boers, T.M., De Graaf, M., Feddes, R.A. and Ben-Asher, J. (1986a) A linear regression model combined with a soil water balance model to design micro-catchments for water harvesting in arid zones. Agricultural Water Management 11, 187-206.

Boers, T.M., Zondervaan, K. and Ben-Asher, J. (1986b) Micro-catchment-water-harvesting (MCWH) for arid zone development. Agricultural Water Management 12, 21-39.

Bruins, H.J., Evenari, M. and Nessler, U. (1986) Rainwater harvesting agriculture for food production in arid zones: the challenge of the African famine. Applied Geography 6, 13-33.

Brunner, U. and Haefner, H. (1986) The successful floodwater farming systems of the Sabeans, Yemen Arab Republic. Applied Geography 6, 77-89.

Critchley, W. and Siegert, K. (1991) Water Harvesting: a Manual for the Design and Construction of Water Harvesting Schemes for Plant Production. AGL Miscellaneous Paper No. 17. Food and Agriculture Organization of the United Nations (FAO), Rome, Italy. 
De Pauw, E., Oweis, T. and Yousef, J. (2008) Integrating expert knowledge in GIS to determine biophysical potential for water harvesting: a case study for Syria. The Comprehensive Assessment of Water Management in Agriculture, Research Report. International Center for Agricultural Research in the Dry Areas (ICARDA), Aleppo, Syria.

El-Naggar, S., Perrier, E. and Shykhoun, M. (1988) Evaluation of farm resource management in the north-west coast of Egypt. In: Proceedings of Workshop for the Northwest Coastal Region. Alexandria/Mersa Matrough, Egypt, April 1988. ARC-SWRI/ICARDA-FRMP.

Ennabli, N. (1993) Les Amenagements Hydrauliques et Hydro-Agricoles en Tunisie. Institut National Aronomique de Tunis, Tunisia.

Evenari, M., Shanan, L. and Tadmor, N.H. (1968) 'Runoff farming' in the desert. I. Experimental layout. Agronomy Journal 60, 29-32.

Evenari, M., Shanan, L. and Tadmor, N.H. (1971) The Negev, the Challenge of a Desert. Harvard University Press, Cambridge, Massachusetts, USA.

Falkenmark, M., Fox, P., Persson, G. and Rockström, J. (2001) Water Harvesting for Upgrading of Rainfed Agriculture: Problems Analysis and Research Needs. Stockholm International Water Institute, Stockholm, Sweden.

FAO (Food and Agriculture Organization of the United Nations) (1994) Water Harvesting for Improved Agricultural Production. Proceedings of the FAO Expert Consultation, Cairo, Egypt, 21-25 November 1993. Water Reports 3. FAO, Rome, Italy.

FAO (Food and Agriculture Organization of the United Nations) (2001) Water Harvesting in Western and Central Africa. RAF/Publication, FAO, Rome, Italy.

Frasier, G.W. and Myer, L.E. (1983) Handbook of Water Harvesting. Agricultural Handbook No. 600. US Department of Agriculture, Agricultural Research Service, USA.

Hatibu, N., Mutabazi, K., Senkondo, E.M. and Msangi, A.S.K. (2006) Economics of rainwater harvesting for crop enterprises in semi-arid areas of East Africa. Agricultural Water Management 80, 74-86.

Joshi, P.K., Jha, A.K., Wani, A.P., Joshi, L. and Shiyani, R.L. (2005) Meta-analysis to assess impact of watershed program and people's participation. Comprehensive Assessment of Water Management in Agriculture. Research Report 8. IWMI, Colombo, Sri Lanka.

Kolarkar, A.S., Murthy, K. and Singh, N. (1983) Khadin - a method of harvesting water for agriculture in the Thar desert. Journal of Arid Environment 8, 59-66.

Kutsch, H. (1983) Currently used techniques in rainfed water-concentrating. Applied Geography and Development 21, 108-117.

Li, F., Cook, S., Geballe, G.T. and Burch, W.R. Jr (2000) Rainwater harvesting agriculture: an integrated system for water management on rainfed land in China's semi-arid areas. AMBIO 29(8), 477-483.

Nasri, S. (2002) Hydrological effects of water harvesting techniques. PhD thesis, Department of Water Resources Engineering, Land Institute of Technology, Sweden.

Oweis, T. and Taimeh, A. (1996) Evaluation of a small basin water-harvesting system in the arid region of Jordan. Water Resources Management 10, 21-34.

Oweis, T. and Taimeh, A. (2001) Farm water-harvesting reservoirs: issues of planning and management in dry areas. In: Adeel, Z. (ed.) Integrated Land Management in Dry Areas. Proceedings of a Joint UNU-CAS International Workshop, Beijing, China, 8-13 Sept 2001. UNU, Tokyo, Japan, pp 165-182.

Oweis, T., Hachum, A. and Kijne, J. (1999) Water Harvesting and Supplemental Irrigation for Improved Water Use Efficiency in the Dry Areas. SWIM Paper 7. International Water Management Institute (IWMI), Colombo, Sri Lanka.

Oweis, T., Prinz, D. and Hachum, A. (2001) Water Harvesting: Indigenous Knowledge for the Future of the Drier Environments. International Center for Agricultural Research in the Dry Areas (ICARDA), Aleppo, Syria.

Oweis, T., Hachum, A. and Bruggeman, A. (eds) (2004) Indigenous Water Harvesting Systems in West Asia and North Africa. International Center for Agricultural Research in the Dry Areas (ICARDA), Aleppo, Syria.

Pacey, A. and Cullis, A. (1986) Rainwater Harvesting: the Collection of Rainfall and Runoff in Rural Area. IT Publications, London, UK.

Perrier, E.R. (1988) Opportunities for the productive use of rainfall normally lost to cropping for temporal or spatial reasons. In: Bidinger, F.R. and Johansen, C. (eds) Drought Research Priorities for the Dryland Tropics. International Crops Research Institute for the Semi-Arid Tropics (ICRISAT), Patancheru, India.

Prinz, D. (1996) Water harvesting - past and future. In: Pereira, L.S. (ed.) Sustainability of Irrigated Agriculture. Proceedings of NATO Advanced Research Workshop, Vimiero, 21-26 March 1994. Balkeman, Rotterdam, the Netherlands, pp. 135-144. 
Rees, D.J., Qureshi, Z.A., Mehmood, S. and Raza, S.H. (1991) Catchment basin water harvesting as a means of improving the productivity of rain-fed land in upland Balochistan. Journal of Agricultural Science, Cambridge 116, 95-103.

Reij, C., Mulder, P. and Begemann, L. (1988) Water Harvesting for Plant Production. Technical Paper No. 91. World Bank, Washington, DC, USA.

Rockström, J., Barron, J. and Fox, P. (2001) Rainwater management for increased productivity among smallholder farmers in drought prone environments. In: Proceedings of the 2nd WARFSA/WaterNet Symposium 'Integrated Water Resources Management: Theory, Practice, Cases'. Cape Town, UNESCO, 30-31 October 2000, pp. 319-330.

Rodriguez, A., Shah, N.A., Afzul, M. and Mustafa, U. (1996) Is water-harvesting in valley floors a viable option for increasing cereal production in Highland Baluchistan, Pakistan? Experimental Agriculture 32, 305-315.

Somme, G., Oweis, T., Abdulal, A., Bruggemen, A. and Ali, A. (2004) Microcatchment Water Harvesting for Improving Vegetative Cover in the Syrian Badia. On-farm Water Husbandry in WANA Series Report No. 3. International Center for Agricultural Research in the Dry Areas (ICARDA), Aleppo, Syria.

Tadmor, N.H., Evenari, M. and Shanan, L. (1970) 'Runoff farming' in the desert. IV. Survival and yields of perennial range plants. Agronomy Journal 62, 695-699.

Tauer, W. and Humborg, G. (1992) Runoff Irrigation in the Sahel Zone. Verlag Josef Margraf Scientific Books, FR, Germany.

UNEP (United Nations Environment Programme) (1983) Rain and Stormwater Harvesting in Rural Areas. UNEP Report. Tycooly International Publishing, Dublin, Ireland.

Wani, S.P., Joshi, P.K., Raju, K.V., Sreedevi, T.K., Wilson, M., Shah, A., Diwakar, P.G., Palanisami, K., Marimuthu, S., Ramakrishna, Y.S., Meenakshi Sundaram, S.S. and D'Souza, M. (2008) Community Watershed as Growth Engine for Development of Dryland Areas - Executive Summary. A Comprehensive Assessment of Watershed Programs in India, International Crops Research Institute for the Semi-Arid Tropics, Patancheru, India.

Yuan, T., Fengmin, L. and Puhai, L. (2003) Economic analysis of rainwater harvesting and irrigation methods, with an example from China. Agricultural Water Management 60 217-226. 